\title{
Spontaneous rupture of a giant gastrointestinal stromal tumor of the jejunum: a case report and literature review
}

\author{
Shun-ichi Misawa ${ }^{1 *}$, Misuzu Takeda ${ }^{1}$, Hiroto Sakamoto ${ }^{1}$, Yasushi Kirii ${ }^{1}$, Hiroyoshi Ota ${ }^{2}$ and Hiroyuki Takagi ${ }^{1}$
}

\begin{abstract}
A few cases of a gastrointestinal stromal tumor (GIST) of the small intestine presenting as rupture have been reported in the medical literature. We report an unusual case of a large GIST of the jejunum that presented as a spontaneous rupture. A 70-year-old man was referred to our hospital because of fever and abdominal pain. An abdominal enhanced computed tomography (CT) scan detected a 10-cm tumor with heterogeneous staining, suggesting necrosis or abscess inside the tumor. The patient was treated with antibiotics but inflammation persisted and an operation was performed. Intraoperative findings showed an outgrowing 10-cm mass in the jejunum near Treitz's ligament. The tumor had ruptured with peritoneal metastasis. The solid parenchyma contained a focal area of necrosis within and the small ulcer located in the wall of the jejunum presented a communication with the large tumor cavity. H\&E staining showed spindle-shaped cell proliferation, and immunohistochemical staining showed results positive for c-kit and CD34. The patient received a diagnosis of a GIST (high-risk group) of the jejunum and was treated with imatinib mesylate. The patient has remained in good health without recurrence or metastasis one year after the surgical procedure.
\end{abstract}

\section{Background}

Gastrointestinal stromal tumors (GISTs) are the most common mesenchymal tumor of the gastrointestinal tract [1]. Most GISTs are $>5 \mathrm{~cm}$ in diameter at the time of diagnosis, with a diameter of $10 \mathrm{~cm}$ being associated with a higher risk of local or distant metastasis. In addition to tumor size, mitotic rate and tumor location, tumor rupture is thought to be a prognostic factor for the outcome of patients with a GIST. Gastrointestinal bleeding is the most common presentation $(50 \%)$ of GISTs and is usually associated with ulceration of the tumor into the lumen $[2,3]$. We report an unusual case of a large GIST of the jejunum that presented as spontaneous rupture.

\section{Case presentation}

A 70-year-old man presented with symptoms of fever and abdominal pain. There were no episodes of gastrointestinal bleeding. The blood pressure was $117 / 86 \mathrm{mmHg}$, the pulse 80 beats per minute, and the temperature $38.2^{\circ} \mathrm{C}$.

\footnotetext{
* Correspondence: 96084sm@jichi.ac.jp

1 Department of Surgery, Matsumoto City Hospital, 4417-180 Hata,

Matsumoto, Nagano 390-1401, Japan

Full list of author information is available at the end of the article
}

Abdominal examination revealed tenderness and muscular defense in the left upper quadrant, and rectal examination revealed an empty ampulla. Blood tests showed a hemoglobin level of $7.2 \mathrm{~g} / \mathrm{dL}$, white blood cell count of $25,490 / \mathrm{mm}^{3}$, and C-reactive protein of $19 \mathrm{mg} / \mathrm{dL}$. An abdominal enhanced computed tomography (CT) scan revealed a $10 \times 10$-cm solid tumor with a low-density area within, suggesting necrosis or abscess; additionally, a liver metastasis was suspected (Figure 1). Upper GI endoscopy revealed no aberrations up to the third portion of the duodenum. Examination of small bowel $x$-ray series revealed no tumor penetration. The mass was suspected as a GIST of the jejunum accompanied by a giant abscess. The patient was treated with intravenous administration of antibiotics and blood transfusion. Subsequent to improvement in his clinical condition and laboratory tests, laparotomy was performed. Intraoperative findings showed mild ascites but there was no blood in the abdominal cavity. We also found an outgrowing $10-\mathrm{cm}$ mass in the jejunum near Treitz's ligament. The tumor was ruptured and peritoneal metastasis was detected around the tumor. Segmental resection of the jejunum with the tumor was performed. The resected mass was a well-circumscribed tumor 


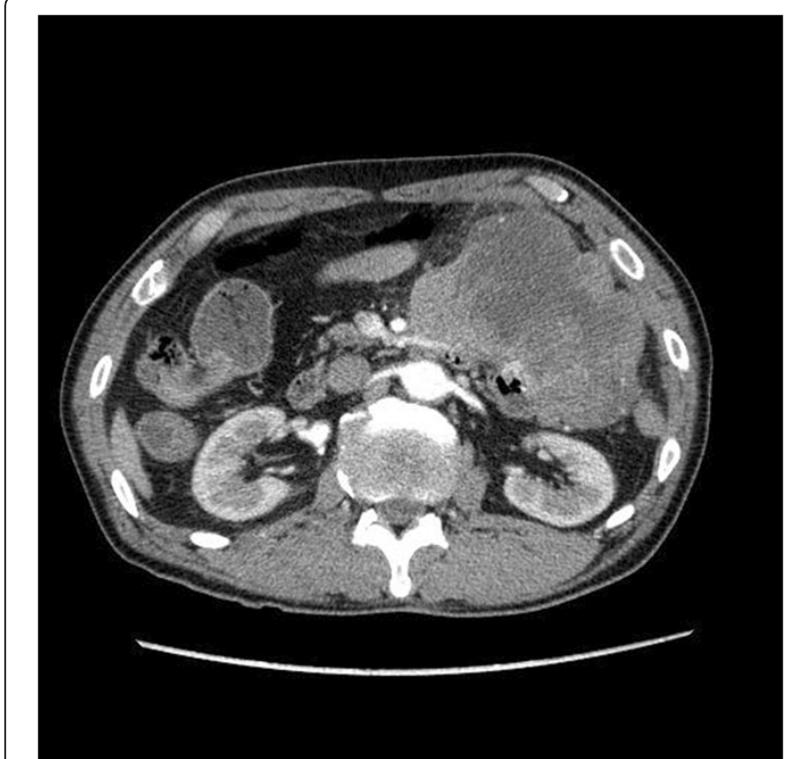

Figure 1 An abdominal enhanced computed tomography scan, revealing a $10 \times 10-\mathrm{cm}$ solid tumor with low-density area within, suggesting necrosis or abscess.

measuring $10 \times 10 \mathrm{~cm}$ and penetrating the jejunum. The solid parenchyma contained central necrosis with a fistula to the lumen of the jejunum (Figure 2). H\&E staining showed spindle-shaped cell proliferation (Figure 3), and immunohistochemical staining showed positive results for c-kit (Figure 4) and CD34 (Figure 5), and a nuclear expression of the proliferation-associated Ki-67-antigen in appro ximately $26 \%$ of the tumor cells (Figure 6). GIST (high-risk group) of the jejunum was diagnosed and treated with imatinib mesylate, $400 \mathrm{mg}$ daily, after the 21 st post-operative day. The patient was discharged after endoscopic dilation

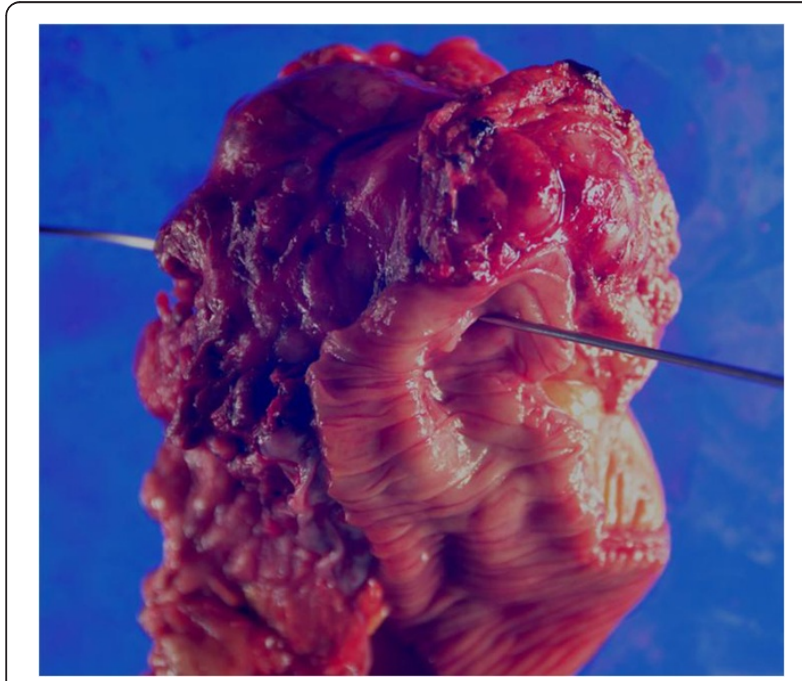

Figure 2 The solid parenchyma contained central necrosis with a fistula to the lumen of the jejunum.

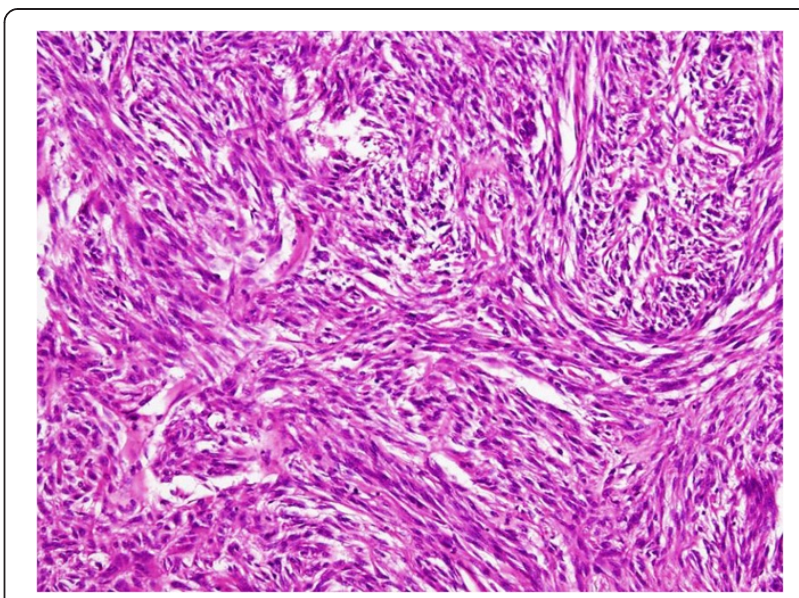

Figure 3 H\&E staining showed spindle-shaped cell proliferation.

for an anastomotic stricture. Medical treatment was continued and the patient was followed up with an abdominal CT scan 12 months after the surgical procedure without any signs of recurrence.

\section{Discussion}

GISTs are visceral tumors arising from any site of the gastrointestinal tract. Approximately 60 to $70 \%$ of cases occur in the stomach, 25 to $35 \%$ in the small intestine, and $10 \%$ in the jejunum, whereas the esophagus, colon, rectum, and appendix, are rarely affected [4]. Bleeding (30 to $40 \%$ of cases) comprises the most common symptom after vague abdominal discomfort. Patients with GIST of the jejunum usually suffer from abdominal pain or have a palpable mass, and also complain of early satiety and abdominal fullness. Pressure necrosis and ulceration of the overlying mucosa may cause gastrointestinal bleeding, and patients who experience a significant blood loss may suffer from malaise and fatigue. Bleeding into the lumen of the

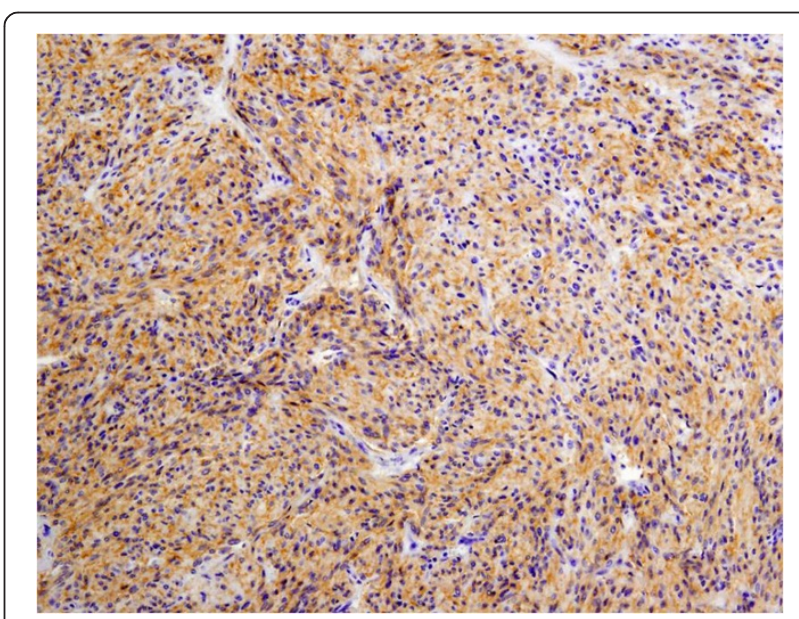

Figure 4 Immunohistochemical staining showed positive results for c-kit. 


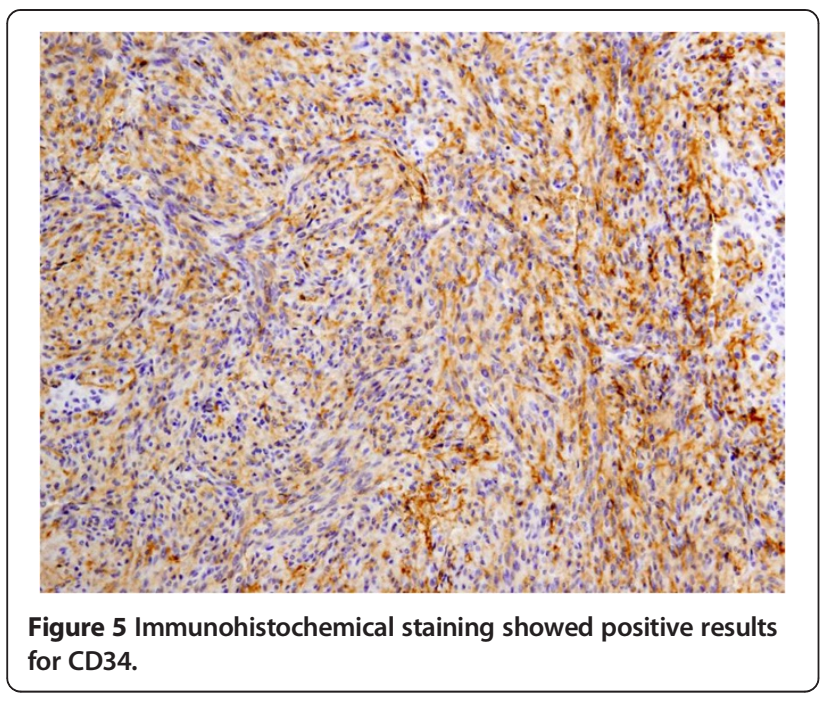

GI tract, causing hematemesis, melena, or anemia, is usually more chronic on presentation [5]. Obstruction may result from intraluminal growth of the tumor or luminal compression from an exophytic lesion. Fever, anorexia, and weight loss are rarely observed, and GISTs originating in the jejunum seldom cause perforation and acute diffuse peritonitis. A few cases have been reported in the English medical literature associated with perforation or rupture of GIST in the small intestine [6-16] (Table 1). Bleeding into the peritoneal cavity due to a ruptured GIST can lead to acute abdominal pain presenting as a surgical emergency $[6,7,10,12,16]$. In addition, only a few cases of GIST of the small intestine accompanied with abscess formation have been reported $[9,14]$. In this case, GIST originating in the jejunum was invaded via a fistula, leading to central necrosis and spontaneous rupture into the peritoneal cavity. For GISTs, prognostic markers that include tumor

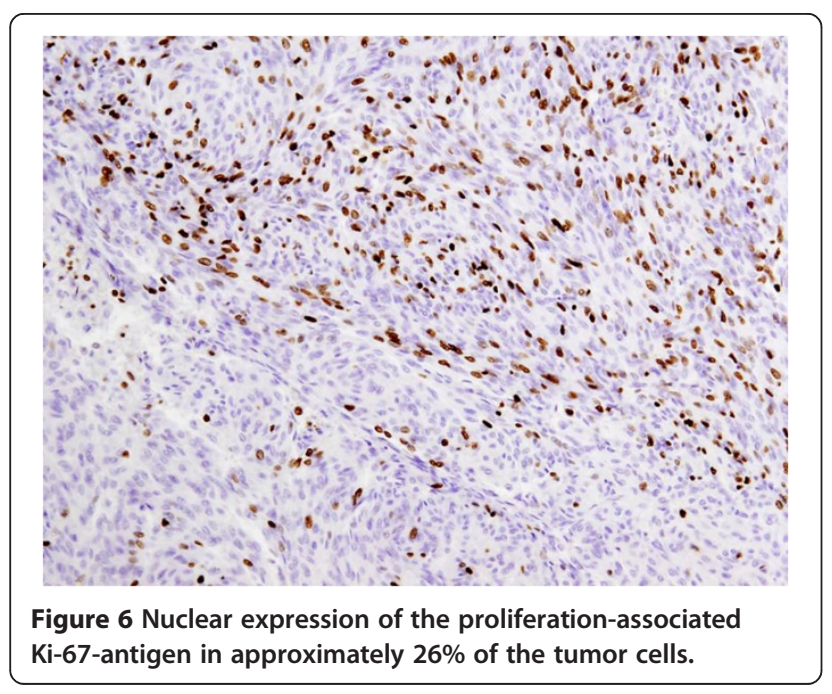

size $>5 \mathrm{~cm}$, mitotic rate $>5 / 50$ high-power fields (HPF), tumor necrosis, and a Ki-67(MIB-1) index of $>10 \%$ are all associated with malignancy of the tumor and high mortality [17-19]. GISTs can be categorized as low or high risk tumors by taking into account the possibility of metastasis or recurrence. However, the main prognostic factor is the mitotic count. A prognostic classification was defined by Fletcher et al. and is widely accepted and used today [17-19] (Table 2). In contrast, the MIB-1 index ( $>22 \%$ in the most active area) was the most powerful predictor of poor survival [20]. The prognosis is dismal when the tumor presents with symptoms or signs such as perforation or rupture, multifocal location, or metastatic lesions. Patients with localized or locally advanced tumors have 46\% 5-year survival, except for patients with a metastatic or multifocal tumor. Those patients have 5-year survival at $24 \%$, probably because of peritoneal dissemination [21].

The introduction of imatinib mesylate, a tyrosine kinase inhibitor targeting KIT has provided a much needed chemotherapeutic option for patients with both resectable and unresectable GISTs. Despite the noted success of imatinib, surgical resection is the main treatment modality for primary GIST of any localization [22,23]. Imatinib treatment of GISTs is a dynamic process with the permanent risk of pharmacoresistance and maximal response within the first six months of therapy [24]. Futhermore, the patients with a primary GIST treated for spontaneous rupture or with rupture occurring during resection have a very high risk of tumor recurrence. These patients are candidates for adjuvant treatment with imatinib [25]. Our case is classified as high-risk GIST with poor prognosis and medical treatment was continued with imatinib; however, no signs of recurrence were observed with abdominal CT scan 12 months after the surgery.

\section{Conclusion}

In conclusion, spontaneous rupture is a rare presentation of GIST and preoperative diagnosis is difficult because of the absence of pathognomonic signs or symptoms. The diagnosis should be suspected whenever there is a presentation of fever and abdominal pain in patients with an intraabdominal mass. In this case, GIST originating in the jejunum led to central necrosis and spontaneous rupture in the peritoneal cavity; however, local excision of the tumor associated with adjuvant therapy with imatinib mesylate was effective and these treatments remain the main modality of treatment of high-risk GISTs.

\section{Consent}

Written informed consent was obtained from the patient for publication of this report and any accompanying images. 
Table 1 Summary of spontaneous ruptured gastrointestinal stromal tumor (GIST) of small intestine in the english medical literature

\begin{tabular}{|c|c|c|c|c|c|c|c|c|c|c|c|c|c|c|}
\hline & $\begin{array}{c}\text { Author } \\
\text { (reference) }\end{array}$ & Year & Age & Sex & Location & Symptoms & $\begin{array}{l}\text { Diagnosis } \\
\text { modality }\end{array}$ & $\begin{array}{l}\text { Intra-abdominal } \\
\text { bleeding }\end{array}$ & $\begin{array}{l}\text { Abscess } \\
\text { formation }\end{array}$ & $\begin{array}{l}\text { Intra-abdominal } \\
\text { dissemination }\end{array}$ & $\begin{array}{l}\text { Mitotic } \\
\text { count }\end{array}$ & $\begin{array}{l}\text { Size } \\
(\mathrm{cm})\end{array}$ & Treatment & Outcome \\
\hline 1 & Ajduck M [6] & 2004 & 60 & $\mathrm{~F}$ & jejunum & $\begin{array}{l}\text { abdominal } \\
\text { pain }\end{array}$ & laparotomy & + & - & - & $3 / 50 \mathrm{HPF}$ & 7.5 & $S R$ & $\mathrm{~N} / \mathrm{A}$ \\
\hline 2 & $\begin{array}{l}\text { Cegarra- } \\
\text { NavarroMF [7] }\end{array}$ & 2005 & 76 & M & jejunum & $\begin{array}{l}\text { abdominal } \\
\text { pain }\end{array}$ & CT & + & - & - & $<5 / 50 \mathrm{HPF}$ & 6 & $S R$ & $\begin{array}{l}31 \text { months } \\
\text { ANED }\end{array}$ \\
\hline 3 & Efremidou El [8] & 2006 & 66 & M & ileum & $\begin{array}{l}\text { abdominal } \\
\text { pain }\end{array}$ & laparotomy & - & - & - & 2/50HPF & $7 \times 5 \times 4$ & $\begin{array}{c}\text { SR+ } \\
\text { Imatinib }\end{array}$ & $\begin{array}{l}44 \text { months } \\
\text { ANED }\end{array}$ \\
\hline 4 & Karagülle E [9] & 2008 & 70 & M & jejunum & $\begin{array}{l}\text { abdominal } \\
\text { pain }\end{array}$ & CT & - & + & - & 0/50HPF & 5 & $S R$ & $\begin{array}{l}13 \text { months } \\
\text { ANED }\end{array}$ \\
\hline 5 & Hirasaki S [10] & 2008 & 87 & $\mathrm{~F}$ & ileum & $\begin{array}{l}\text { abdominal } \\
\text { pain }\end{array}$ & CT & + & - & - & N/A & $13 \times 11$ & $S R$ & $\begin{array}{l}16 \text { months } \\
\text { ANED }\end{array}$ \\
\hline 6 & Ku MC [11] & 2010 & 33 & $\mathrm{~F}$ & jejunum & $\begin{array}{l}\text { abdominal } \\
\text { pain }\end{array}$ & CT & - & - & + & N/A & $\begin{array}{c}6.5 \times \\
5.3 \times 3.9\end{array}$ & $S R$ & $\mathrm{~N} / \mathrm{A}$ \\
\hline 7 & Varras M [12] & 2010 & 28 & $\mathrm{~F}$ & $\mathrm{~N} / \mathrm{A}$ & $\begin{array}{l}\text { abdominal } \\
\text { pain }\end{array}$ & US & + & - & - & $>5 / 50 \mathrm{HPF}$ & 13 & $S R$ & $\begin{array}{l}3 \text { years } \\
\text { ANED }\end{array}$ \\
\hline 8 & Feng F [13] & 2011 & 45 & M & jejunum & $\begin{array}{l}\text { abdominal } \\
\text { pain }\end{array}$ & CT & - & - & - & $<5 / 50 \mathrm{HPF}$ & $10 \times 8$ & $S R$ & $\mathrm{~N} / \mathrm{A}$ \\
\hline 9 & Chen HW [14] & 2011 & 22 & M & jejunum & $\begin{array}{l}\text { abdominal } \\
\text { pain }\end{array}$ & CT & - & + & - & N/A & 5 & $S R$ & $\begin{array}{l}2 \text { months } \\
\text { ANED }\end{array}$ \\
\hline 10 & Memmi N [15] & 2012 & 59 & M & jejunum & $\begin{array}{l}\text { abdominal } \\
\text { pain }\end{array}$ & CT & - & - & - & 7/50HPF & 12 & $S R$ & $\mathrm{~N} / \mathrm{A}$ \\
\hline 11 & Nannini M [16] & 2013 & 45 & $\mathrm{~F}$ & jejunum & $\begin{array}{l}\text { abdominal } \\
\text { pain }\end{array}$ & laparotomy & + & - & + & $2 / 50 \mathrm{HPF}$ & 12 & $\underset{\text { Imatinib }}{\text { SR+ }}$ & $\begin{array}{l}13 \text { months } \\
\text { ANED }\end{array}$ \\
\hline 12 & This case & 2014 & 71 & M & jejunum & $\begin{array}{l}\text { abdominal } \\
\text { pain fever }\end{array}$ & CT & - & - & + & $M I B>26 \%$ & $9 \times 9$ & $\underset{\text { Imatinib }}{\mathrm{SR}+}$ & $\begin{array}{l}12 \text { months } \\
\text { ANED }\end{array}$ \\
\hline
\end{tabular}




\section{Table 2 Prognostic classification of gastrointestinal stromal tumors (GISTs) by Fletcher et al. [17]}

\begin{tabular}{ccc}
\hline Risk of malignancy & Size of tumor $\mathbf{( c m})$ & Mitotic counts (/50HPF) \\
\hline Very low & $<2$ & $<5$ \\
Low & 2 to 5 & $<5$ \\
Intermediate & $<5$ & $<$ to 10 \\
High & 5 to 10 & $>5$ \\
& $>5$ & Any counts \\
& $>10$ & $>10$
\end{tabular}

\section{Abbreviations}

CT: computed tomography; GIST: gastrointestinal stromal tumor; H\&E: hematoxylin and eosin.

\section{Competing interests}

The authors declare that they have no compating interests.

\section{Authors' contributions}

SM was responsible for the writing. MT, HS, YK and HT participated in the clinical management of the patient. $\mathrm{HO}$ carried out the pathological examination. All authors read and approved the final manuscript.

\section{Author details}

'Department of Surgery, Matsumoto City Hospital, 4417-180 Hata, Matsumoto, Nagano 390-1401, Japan. ${ }^{2}$ Department of Biomedical Laboratory Sciences, Shinshu University, School of Medicine, School of health Science, 3-1-1 Asahi, Matsumoto, Nagano 390-8621, Japan.

Received: 17 December 2013 Accepted: 2 May 2014

Published: 21 May 2014

\section{References}

1. Miettinen M, Lasota J: Gastrointestinal stromal tumors: review on morphology, molecular pathology, prognosis, and differential diagnosis. Arch Pathol Lab Med 2006, 130:1466-1478.

2. Rossi $C R$, Mocellin $S$, Mencarelli R, Foletto M, Pilati P, Nitti D, Lise M: Gastrointestinal stromal tumors: from a surgical to a molecular approach. Int J Cancer 2003, 107:171-176.

3. Fletcher CD, Berman JJ, Corless C, Gorstein F, Lasota J, Longley BJ, Miettinen M, O'Leary TJ, Remotti H, Rubin BP, Shmookler B, Sobin LH, Weiss SW: Diagnosis of gastrointestinal stromal tumors: a consensus approach. Int $J$ Surg Pathol 2002, 10:81-89.

4. Connolly EM, Gaffney E, Reynolds JV: Gastrointestinal stromal tumours. $\mathrm{Br} J$ Surg 2003, 90:1178-1186.

5. Rammohan A, Sathyanesan J, Rajendran K, Pitchaimuthu A, Perumal SK, Srinivasan U, Ramasamy R, Palaniappan R, Govindan M: A gist of gastrointestinal stromal tumors: a review. World J Gastrointest Oncol 2013, 5:102-112.

6. Ajduk M, Mikulić D, Sebecić B, Gasparov S, Patrlj L, Erdelez L, Skopljanac A, Staresinić M, Desković S, Sosa T, Sitić S: Spontaneously ruptured gastrointestinal stromal tumor (GIST) of the jejunum mimicking acute appendicitis. Coll Antropol 2004, 28(2):937-941.

7. Cegarra-Navarro MF, de la Calle MA, Girela-Baena E, García-Santos JM, Lloret-Estañ F, de Andrés EP: Ruptured gastrointestinal stromal tumors: radiologic findings in six cases. Abdom Imaging 2005, 30:535-542.

8. Efremidou El, Liratzopoulos N, Papageorgiou MS, Romanidis K: Perforated GIST of the small intestine as a rare cause of acute abdomen: surgical treatment and adjuvant therapy. Case report. J Gastrointestin Liver Dis 2006, 15:297-299.

9. Karagülle E, Türk E, Yildirim E, Gõktürk HS, Kiyici H, Moray G: Multifocal intestinal stromal tumors with jejunal perforation and intra-abdominal abscess: report of a case. Turk J Gastroenterol 2008, 19:264-267.

10. Hirasaki S, Fujita K, Matsubara M, Kanzaki H, Yamane H, Okuda M, Suzuki S, Shirakawa A, Saeki H: A ruptured large extraluminal ileal gastrointestinal stromal tumor causing hemoperitoneum. World J Gastroenterol 2008, 14:2928-2931.

11. Ku MC, Tsai CM, Tyan YS: Multiple gastrointestinal stromal tumors in a patient with type I neurofibromatosis presenting with tumor rupture and peritonitis. Clin Imaging 2010, 34(1):57-59. doi:10.1016/j.clinimag.2009,

12. Varras M, Vlachakos N, Akrivis C, Vasilakaki T, Skafida E: Malignant gastrointestinal stromal tumor presenting with hemoperitoneum in puerperium: report of a case with review of the literature. World I Surg Oncol 2010, 8:95

13. Feng F, Chen F, Chen Y, Liu J: A rare perforated gastrointestinal stromal tumor in the jejunum: a case report. Turk J Gastroenterol 2011, 22:208-212.

14. Chen HW, Lin TY: Tumor abscess formation caused by Morganella morganii complicated with bacteremia in a patient with gastrointestinal stromal tumor. Clin Res Hepatol Gastroenterol 2012, 36:e29-e31.

15. Memmi N, Cipe G, Bektasoglu H, Toydemir T, Toydemir T, Kadioglu H, Bozkurt S, Buyukpinarbasili N, Karatepe O, Muslumanoglu M: Perforated gastrointestinal stromal tumor in the jejunum: a rare cause of acute abdomen. Oncol Lett 2012, 4:1244-1246.

16. Nannini M, Pantaleo MA, Catena F, Romano S, Tondo S, Pirini MG, Lolli C, Maleddu A, Mandrioli A, Gatto L, Saponara M, Pallotti MC, Dei Tos AP, Pinna $A D$, Biasco G: Surgical second-look in high risk gastrointestinal stromal tumor of small intestine: a case report. Int I Surg Case Rep 2013, 4(1):7-10.

17. Fletcher CD, Berman JJ, Corless C, Gorstein F, Lasota J, Longley BJ, Miettinen M, O'Leary TJ, Remotti H, Rubin BP, Shmookler B, Sobin LH, Weiss SW: Diagnosis of gastrointestinal stromal tumors: a consensus approach. Hum Pathol 2002, 33(5):459-465. Review.

18. Emory TS, Sobin LH, Lukes L, Lee DH, O'Leary TJ: Prognosis of gastrointestinal smooth-muscle (stromal) tumors: dependence on anatomic site. Am J Surg Pathol 1999, 23:82-87.

19. Hasegawa T, Matsuno Y, Shimoda T, Hirohashi S: Gastrointestinal stromal tumor: consistent CD117 immunostaining for diagnosis, and prognostic classification based on tumor size and MIB-1 grade. Hum Pathol 2002, 33:669-676.

20. Carrillo R, Candia A, Rodriguez-Peralto JL, Caz V: Prognostic significance of DNA ploidy and proliferative index (MIB-1 index) in gastrointestinal stromal tumors. Hum Pathol 1997, 28:160-165.

21. Crosby JA, Catton CN, Davis A, Couture J, O'Sullivan B, Kandel R, Swallow CJ: Malignant gastrointestinal stromal tumors of the small intestine: a review of 50 cases from a prospective database. Ann Surg Oncol 2001, 8:50-59.

22. Demetri $G D$, von Mehren $M$, Blanke $C D$, Van den Abbeele $A D$, Eisenberg $B$, Roberts PJ, Heinrich MC, Tuveson DA, Singer S, Janicek M, Fletcher JA, Silverman SG, Silberman SL, Capdeville R, Kiese B, Peng B, Dimitrijevic S, Druker BJ, Corless C, Fletcher CD, Joensuu H: Efficacy and safety of imatinib mesylate in advanced gastrointestinal stromal tumors. $N$ Engl $\mathrm{J}$ Med 2002, 347:472-480.

23. Verweij J, Casali PG, Zalcberg J, LeCesne A, Reichardt P, Blay JY, Issels R, van Oosterom A, Hogendoorn PC, Van Glabbeke M, Bertulli R, Judson I: Progression-free survival in gastrointestinal stromal tumours with high-dose imatinib: randomised trial. Lancet 2004, 364:1127-1134.

24. Rutkowski P, Gronchi A, Hohenberger P, Bonvalot S, Schöffski P, Bauer S, Fumagalli E, Nyckowski P, Nguyen BP, Kerst JM, Fiore M, Bylina E, Hoiczyk M, Cats A, Casali PG, Le Cesne A, Treckmann J, Stoeckle E, de Wilt JH, Sleijfer S, Tielen R, van der Graaf W, Verhoef C, van Coevorden F: Neoadjuvant imatinib in locally advanced gastrointestinal stromal tumors (GIST): the EORTC STBSG experience. Ann Surg Oncol 2013, 20:2937-2943.

25. Hohenberger $\mathrm{P}$, Ronellenfitsch U, Oladeji O, Pink D, Ströbel P, Wardelmann $E$, Reichardt $P$ : Pattern of recurrence in patients with ruptured primary gastrointestinal stromal tumour. Br J Surg 2010, 97(12):1854-1859.

doi:10.1186/1477-7819-12-153

Cite this article as: Misawa et al: Spontaneous rupture of a giant gastrointestinal stromal tumor of the jejunum: a case report and literature review. World Journal of Surgical Oncology 2014 12:153. 